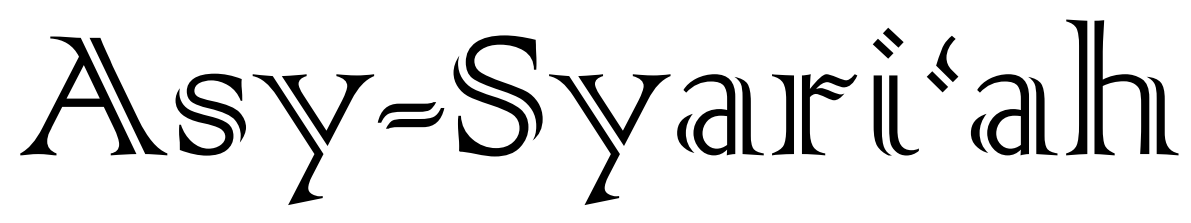

- $\quad$ The Role of Religious Court in Islamic Law Reform in Indonesia

$(125-134)$ Amran Suadi

- Rechtvinding tentang Waris Beda Agama di Pengadilan Agama ( $135-158)$ Kota Bandung Siah Khosyi'ah dan Aan Tsamrotul Fuadah

- Dualisme Kedudukan dan Tanggung Jawab Notaris dalam ( $159-170)$ Tatanan Sistem Hukum Nasional Isis Ikhwansyah dan Indra Prayitno

- Nilai-Nilai Keislaman dalam Konstitusi Kesultanan Ngayogyakarta Hadiningrat

Abdul Rohim Al Wafi

- Anotasi Putusan Dissenting Opinion dalam Putusan Kasasi Taufik Maulani

- Dampak Poligami Siri Terhadap Kehidupan Keluarga di Desa Cigugur Girang, Bandung Barat Ade Darmawijaya

- Azas-Azas dan Landasan Distribusi Pendapatan dalam Islam $(221-232)$ Rani Mulyani dan Iwan Setiawan

- Eksistensi Riba dalam Investasi Wakaf Uang di Luar Bank (233-244) Syari'ah

Khoir Affandi

- Hak Pendidikan bagi Penyandang Disabilitas dalam Perspektif Hukum Perdata dan Hak Asasi Manusia

Ikbar Maulana Malik

- Perspektif Hukum Islam dalam Penyelesaian Sengketa Melalui ( $257-280$ ) Mediasi di Badan Penyelesaian Sengketa Konsumen Kota Mataram Irma Istihara Zain 


\section{Asy-Syauri'ah}

Volume 21, Number 2, 2019

\section{EDITOR-IN-CHIEF}

Ine Fauzia

\section{EDITORIAL BOARD}

Sofyan al-Hakim, UIN Sunan Gunung Djati Bandung, Indonesia Deni Kamaludin Yusup, UIN Sunan Gunung Djati Bandung, Indonesia Meria Utama, Fakultas Hukum Univrsitas Sriwijaya, Indonesia Dewi Mayaningsih, UIN Sunan Gunung Djati Bandung, Indonesia Andrey Sujatmiko, Fakultas Hukum Universitas Trisakti, Jakarta, Indonesia Hetty Hassanah, Universitas Komputer Indonesia, Indonesia

\section{PEER-REVIEWERS}

Muhammad Irfan Helmy, IAIN Salatiga, Semarang, Indonesia Ahmad Ali Nurdin, UIN Sunan Gunung Djati Bandung Tajul Arifin, UIN Sunan Gunun Djati Bandung, Indonesia Mohamad Anton Athoillah, UIN Sunan Gunung Djati Bandung, Indonesia Mrs. Renny Supriyatni, Universitas Padjadjaran, Indonesia Ahmad Tholabi Karlie, UIN Syarif Hidayatullah Jakarta, Indonesia Ija Suntana, UIN Sunan Gunung Djati Bandung, Indonesia Zezen Zaenal Mutaqin, University of California, Los Angeles, United States Ahmad Fathonih, UIN Sunan Gunung Djati Bandung, Indonesia Rahman Syamsuddin, Universitas Islam Negeri Alauddin Makassar, Indonesia

\section{PROOFREADER/DESIGN COVER}

Nanang Sungkawa

\section{LAYOUT EDITOR}

Opik Rozikin

Asy-Syari' ah has been accredited based on the determination of Director General of Research and Development Strengthening, Ministry of Research, Technology and Higher Education of Republic of Indonesia, No. 14/E/KPT/2019 (valid until 2023). 


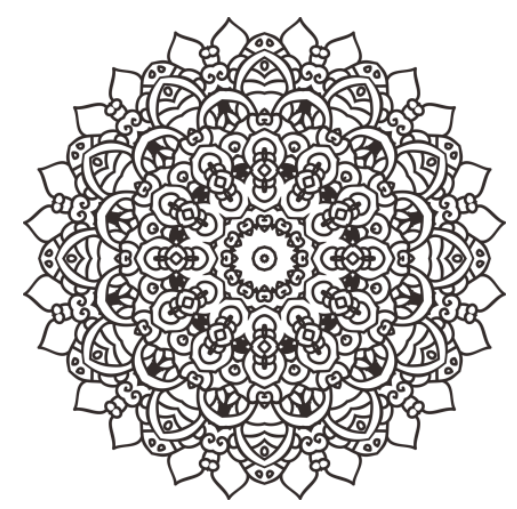

\title{
HAK PENDIDIKAN BAGI PENYANDANG DISABILITAS DALAM PERSPEKTIF HUKUM PERDATA DAN HAK ASASI MANUSIA
}

\author{
Ikbar Maulana Malik \\ KUA Kecamatan Ujungberung, Bandung \\ Email: Ikbarmaulana21@gmail.com
}

\begin{abstract}
Law regulates all aspects of life, one of which is education rights. Education is given to humans not only for non-disabled people (normal) but disability has the right of education because this indicates that there is justice and in order to achieve the objectives of the rule of law, namely to educate the life of the nation. However, there are several issues or cases that still seem to ignore the right of education for persons with disabilities. This study uses a method in the form of Descriptive Analysis, the type of data carried out is qualitative. Then the data source used is primary. Furthermore, in the technique of data collection is done by searching in books, articles, journals and other literacy. Then analyze the data by understanding and formulating conclusions on the problems used in the formulation of the problem. The results of this study are that there are still several factors that make the cause of not fulfilling the right to education for persons with disabilities then in the review of civil law and human rights very supportive for the implementation of the right to education for persons with disabilities given fully and thoroughly.
\end{abstract}

Keywords: educational rights, civil law, human rights 
Abstrak: Hukum mengatur segala aspek kehidupan salah satunya hak pendidikan. Pendidikan diberikan kepada manusia bukan hanya bagi non disabilitas (normal) tetapi disabilitaspun mempunyai hak pendidikan sebab hal ini menandakan ada keadilan dan demi mencapai tujuan Negara hukum yaitu mencerdaskan kehidupan bangsa. Namun ada beberapa isu atau kasus yang masih terkesan tidak memperdulikan hak pendidikan bagi penyandang disabilitas. Penelitian ini menggunakan metode berupa Deskriptif Analisis, Jenis data yang dilakukan bersifat kualitatif. Kemudian Sumber data yang di pakai yaitu primer Selanjutnya dalam tehnik pengumpulan data dilakukan dengan cara mencari dalam buku-buku, artikel, jurnal dan literasi lainnya. Kemudian dilakukan analisis data dengan memahami dan merumuskan kesimpulan terhadap masalah yang dijadikan dalam perumusan masalah. Hasil dari penelitian ini adalah masih ada beberapa faktor yang menjadikan sebab tidak terpenuhinya secara efektif tentang hak pendidikan bagi penyandang disabilitas kemudian dalam tinjauan hukum perdata dan Hak Asasi Manusia sangat mendukung atas implementasi hak pendidikan bagi penyandang disabilitas diberikan secara penuh dan menyeluruh.

Kata Kunci: hak pendidikan, hukum perdata, HAM 


\section{Pendahuluan}

Menurut Charles E Merriam bahwa fungsi adanya Negara itu adalah untuk memberikan rasa keamaanan, ketertiban, sejahtera bagi semua pihak (tanpa memandang strata sosila,ekonomi dan lain-lain) dan terakhir kebebasan. Negara memiliki masyarakat yang perlu diberikan pelayanan yang berkualitas, hal ini merupakan tugas pemerintah dalam menyelenggarakan fungsi Negara tersebut. Tentunya dala menjalankan fungsi Negara tersebut, pemerintah memiliki tugas yang memiliki nilai yang luhur baik secara sosial atau agama sebab hal ini demi tercapainya tujuan Negara. Tujuan Negara dalam pandangan Miriam Budiardjo ${ }^{1}$ adalah menciptakan kebahagiaan bagi rakyatnya (bonum publicum, common good, common wealth).

Pemerintah melalui Undang Undang Dasar 1945 pada pasal 31 ayat (1) bahwa setiap warga Negara Indonesia memiliki hak atas pendidikan. Sehingga dengan adanya aturan tersebut melahirkan sebuah aturan Undang Undang Nomor 20 Tahun 2003 tentang Pendidikan Nasional. Akan tetapi dalam Undang Undang tersebut hanya mengatur banyak tentang hak pendidikan bagi manusia non disabilitas (normal), sedangkan dalam mengatur hak pendidikan bagi manusia penyandang disabilitas adalah Undang Undang Nomor o8 Tahun 2016 Tentang Disabilitas yang tepatnya di pasal 5 huruf (e) yang berbunyi bahwa penyandang disabilitas memiliki hak yaitu hak pendidikan. Pendidikan adalah usaha yang sadar dalam menciptakan manusia yang berakhlak dan beradab. Hak pendidikan tidak memandang bulu artinya semua manusia di bumi ini sangat berhak mendapatkan hak pendidikan. Kemudian pada pasal 4 Undang Undang tentang disabilitas tersebut dikatakan bahwa disabilitas memiliki macam-macam bentuk, yaitu disabilitas fisik, intelektual, mental dan sensorik.

Dalam pandangan psikologis disabilitas disebut dengan prilaku abnormal. Perilaku abnormal adalah gangguan yang terdapat secara prilaku jarang ditemukan, melanggar norma, distress pribadi dan disfunsi prilaku atau disabilitas. ${ }^{2}$ Kemudian dalam hal dunia pendidikan untuk melaksanakan aturan ini tentunya pemerintah memerlukan eksekutor, yaitu guru. Guru adalah tenaga masyarakat yang mengabdikan diri dan diangkat untuk menunjang penyelenggaraan pendidikan ${ }^{3}$. Jadi, pemerintah membuat Undang-undang Nomor o8 Tahun 2016 Tentang Disabilitas yang bersifat perintah dan larangan yang harus dilaksanakan atau menjadi wasilah oleh salah satu profesi yang berkompeten, yaitu guru. Hal ini selaras dengan salah satu kaidah Fiqiyyah, yaitu: "Al amru Bisyyai, amru biwasailihi" Artinya "dalam memerintah sesuatu harus disertai dengan wasilahnya".

Akan tetapi dalam kenyataannya, masih banyak para guru-guru disekolah atau bahkan orangtua dirumah masih kurang peka dan peduli dalam memenuhi hak pendidikan bagi penyandang disabilitas, seperti isu: Pertama, Terjadi sebuah pembunuhan yang

\footnotetext{
${ }^{1}$ Miriam Budiardjo, Dasar-Dasar Ilmu Politik (Jakarta: Gramedia Pustaka Utama, 2008), hlm. 54.

${ }^{2}$ Gerald C. Davison, Psikologi Abnormal (Jakarta: Rajagrafindo, 2006), HIm. 4-6.

${ }^{3}$ Pasal 1 ayat 5 Undang Undang Nomor 20 Tahun 2003 Tentang Sistem Pendidikan Nasional
} 
dilakukan oleh penyandang disabilitas, kasus ini walaupun tidak ada hubungannya dengan pendidikan akan tetapi dengan cara diberikan hak pendidikan merupakan salah satu pencegahan bahwa membunuh itu dilarang oleh Negara dan agama. ${ }^{4} K e d u a$, Susahnya masuk keperguruan tinggi bagi penyandang disabilitas. ${ }^{5}$ Ketiga, Hak pendidikan yang susah diakomodir karena dalam Rencana Peraturan Perundangundangan tidak diatur sehingga ruh dari Undang Undang Nomor 08 Tahun 2016 Menjadi hilang. ${ }^{6}$

Dari beberapa kasus diatas dapat disimpulkan secara sementara bahwa hak pendidikan bagi penyandang disabilitas belum terpenuhi secara maksimal. Sehingga lahirlah beberapa pertanyaan yaitu faktor apa saja yang menjadi penghambat dalam pemenuhan hak pendidikan bagi penyandang disabilitas, Bagaimana tinjauan hukum perdata dan HAM atas hak pendidikan bagi penyandang disabilitas.

Perlunya ada anggapan dan kesadaran masyarakat luas secara merata bahwa hak pendidikan sangat diperlukan bagi penyandang disabilitas terlepas dari disabilitas apapun agar para penyandang disabilitas bisa lebih dihargai keberadaannya di lingkungan dan bisa menjalani kehidupan berbangsa dan bernegara secara sejahtera.

Ketertarikan peneliti menganalisis hal ini karena peneliti merasakan beberapa orang yang ada disekitar peneliti sangat perlu membutuhkan perlindungan hukum atas hak pendidikan bagi penyandang disabilitas dan banyaknya stigma negatif dari masyarakat umum yang menjadikan penyandang disabilitas adalah salah satu sampah masyarakat atau dalam perspektif bahasa sunda "nyenyempit alam dunya" artinya hanya menyempitkan dunia ini.

\section{Faktor Penghambat Pemenuhan Hak Pendidikan Bagi Penyandang Disabilitas}

Indonesia merupakan Negara yang memiliki citra berbeda-beda tapi memiliki satu tujuan bersama, yaitu merdeka. Sejak dahulu para pejuang secara tidak langsung mengajarkan kepada penerus bangsa untuk bisa saling menghargai satu sama lain baik berbeda agama, warna kulit, sosial, ekonomi dan lain-lain. Sebab para pejuang dalam memerdekakan Indonesia tak pandang bulu siapa pun boleh memperjuangkan Indonesia agar bisa bebas dari renggutan penjajah.

${ }^{4}$ Fachmi Rachman, "Reka Ulang Pembunuhan Sadis Di Balikpapan Terkendala Komunikasi, Ini Penyebabnya Artikel Ini Telah Tayang Di Tribunkaltim.Com, "kaltim.tribunnews.com,2013, https:// kaltim.tribunnews.com/2019/07/13/reka-ulang-pembunuhan-sadis-di-balikpapan-terkendala-komunikasi-inipenyebabnya. (Diakses Pada Tanggal 23-07-2019 Pukul 15.00 Wib)

${ }^{5}$ Widia Primastika, "Penyandang Disabilitas Masih Sulit Mengakses Perguruan Tinggi," tirto.id, 2018, https://tirto.id/penyandang-disabilitas-masih-sulit-mengakses-perguruan-tinggi-c6am diakses pada tanggal 23-07-2019 Pukul 15.10 Wib.

6 DPP Partai Keadilan Sejahtera, "Hak Pendidikan Bagi Penyandang Disabilitas Sulit Terakomodir," Berita PKS, 2018, http://pks.id/content/hak-pendidikan-bagi-penyandang-disabilitas-sulit-terakomodir (Diakses Pada Tanggal 23-07-2019 Pukul 15:15 Wib). 
Dalam penegakkan hukum juga tak memandang bulu karena ada asas persamaan hukum. Julita Melissa Walukow ${ }^{7}$ berpendapat bahwa equality before the law atau persamaan dalam hukum secara sederhananya adalah semua orang sama derajatnya dihadapan hukum dan salah satu asas yang sangat penting dalam hukum era sekarang.

Pada dasarnya hukum itu tidak akan berjalan dengan secara otomatis tanpa adanya kesadaran hukum dari masyarakat. Menurut Sudikno Mertokusumo ${ }^{8}$ dikatakan bahwa kesadaran hukum itu ada pada setiap insan manusia secara bukan hanya ada pada ahli hukum. Salah satu hukum yang perlu ditegakkan dan disadari adalah pemenuhan Hak.

Hak adalah sebuah arah yang memiliki manfaat untuk menjadikan petunjuk atas cara melindungi, kebabasan, dan menjaga hakikat manusia itu sendiri. Ada beberapa unsur dalam hak, yaitu yang memiliki hak, implementasi hak, subjek dalam menegakkan hak. Unsur-unsur ini menjadi definisi awal tentang hak. ${ }^{9}$

Dalam hal pemenuhan hak pendidikan bagi penyandang disabilitas terkadang terdapat beberapa faktor yang menjadi sebuah penghambat, yaitu: Faktor Hukum, Secara yuridis Undang Undang Nomor o8 Tahun 2016 Tentang Disabilitas merupakan perubahan dari Undang Undang Nomor 4 Tahun 1977 Tentang Penyandang Cacat. Ada nilai baik dalam perubahan tersebut. Pertama, penamaan yang awalnya "cacat" yang kurang manusiawi diganti menjadi "disabilitas" yang lebih manusiawi. Kedua referensi dalam penyusunan Undang Undang baru lebih banyak baik dari skala nasional atau internasional. Sehingga secara kualitas, materi Undang Undang Nomor o8 Tahun 2016 menjadi lebih bermakna. Ketiga Undang Undang No 04 Tahun 1977 terbatas dalam memberikah perlindungan atas hak-hak bagi penyandang disabilitas sedang dalam Undang Undang Nomor o8 Tahun 2016 lebih mendekati pemenuhan hak-hak bagi penyandang disabilitas. ${ }^{10}$

Akan tetapi dalam pandangan peneliti ada nilai kekurangannya juga sebetulnya dalam Undang Undang Nomor 08 Tahun 2016, yaitu pada pasal 10 huruf (a) tentang hak pendidikan. Dalam pasal tersebut kenapa tidak diberikan metode atau cara-cara dalam memberikan pendidikan inklusif atau khusus. Contoh, bagi disabilitas disleksia (siswa yang tidak bisa membaca) diberikan pendidikan inklusif, akan tetapi tidak dijelaskan dan tidak diatur bagaimana caranya menyampaikan materi pelajaran kepada siswa tersebut dengan menggunakan pendidikan inklusif.

7 Julita Melissa Walukow, "Perwujudan Prinsip Equality Before The Law Bagi Narapidana Di Dalam Lembaga Permasyarakatan Di Indonesia," Jurnal Ilmiah Lex et Societatis Volume 1, no. 1 (2013): hlm. 163.

${ }^{8}$ Sudikno Mertokusumo, Teori Hukum (Yogyakarta: Cahaya Atma Pustaka, 2012), HIm. 17.

${ }^{9}$ Anonimous, "Demokrasi, HAM, Masyarakat Madani, Diunduh melalui http://digilib.unila.ac.id /1252 18/BAB\%20ll.pdf Pada Tanggal 23-07-2019, Pukul 20:00 WIB." (2011).

${ }^{10}$ Naskah Akademik Undang Undang Nomor 08 Tahun 2016 diakses pada Tanggal 25 Juli 2019 Pukul 23:00 WIB 
Faktor Sarana Di Sekolah. Guru memiliki tanggung jawab dan kewajiban sebagai sarana dalam memberikan hak pendidikan bagi siswanya. Tanpa ada guru maka pendidikan di Indonesia tak akan berjalan. Sehingga Undang Undang yang berkaitan dengan pendidikan tak ada gunanya. Sehingga ada adagium yang berbunyi "orang-orang hebat menghasilkan karya berkualitas, tetapi guru yang berkualitas pasti menghasilkan orang-orang hebat".

Akan tetapi masih banyak disekolah-sekolah baik disekolah regular yang memiliki siswa disabilitas atau sekolah SLB yang memiliki guru-guru tidak relevan dengan latarbelakang studinya kurang optimal dalam memberikan hak pendidikan atau mungkin saja, karena gaji/pendapatan nya kurang sehingga mempengaruhi kinerja sebagai guru.

Faktor Kehidupan Masyarakat. Kembali lagi pada kesadaran hukum. Kesadaran hukum harus disandingkan dengan hati nurani agar tercipta sebuah keharmonisan. Ketertinggalan masyarakat khususnya desa mengakibatkan kurang pahamnya diagnosis disabiltas. Contoh diagnosis bagi disabilitas disleksia. Secara kasat mata penyandang disleksi normal-normal saja, akan tetapi ketika disuruh membaca maka akan merasakan kesulitan yang sangat luar biasa. Masyarakat desa tak akan paham dengan disleksia, jangankan paham namanya juga sangat asing ditelinga mereka.

Kemudian bagi masyarakat desa yang lebih diutamakan untuk mencari sekolah adalah biaya iuran yang termurah sehingga kualitas sekolah bukan dijadikan nomor utama. Jadi, masyarakatpun harus sadar dan paham akan anak-anaknya yang disabilitas perlu disekolahkan dimana dan bagi masyarakat juga jangan ada stigma negative untuk orang yang menyandang disabilitas, sebab hal itu akan membuat penyandang disabilitas menjadi down dan tidak ingin berkembang.

Faktor Keluarga. Keluarga adalah perbuatan hukum bagi setiap insan yang berusaha menjalankan amanat Allah Swt dan sunnah Rasulullah Saw. Akan tetapi tak dapat dipungkiri bahwa keluarga menjadi awal kebaikan dan keburukan sebab keluarga menjadi tolak ukur utama menjadikan anaknya berkualitas atau tidak. Ketika keluarga mendukung (Support) segala keinginan dan kekurangan anaknya maka keluarga tersebut menjadikan sumbu utama kepercayaan diri bagi anaknya dan sebaliknya. Begitupun bagi anak yang menyandang disabilitas, tidak sedikit keluarga tidak memahami dan bahkan memandang aib ketika dianugrahi anak penyandang disabilitas. Padahal Allah swt hanya melihat hati manusia bukan secara fisik dan bagi penyandang disabilitas sebetulnya memiliki kekurangan dan kelebihan yang secara hakikatnya Allah swt menitipkan beberapa pesan, seperti: bagi keluarga yang memiliki anak penyandang disabilitas, maka Allah memberi pesan melalui ujian apakah keluarga tersebut sabar dan menerima apa adanya yang Allah Swt berikan kepadanya atau tidak, jika sabar dan menerima maka pahala menjadi jaminannya dan sebaliknya.

Kemudian kurang pahamnya masyarakat umum atas kebutuhan seksual penyandang disabilitas. Tak heran jika penyandang disabilitas melakukan hal aneh yang 
berhubungan dengan seksual seperti contoh lumrahnya adalah masturbasi. Sebagian masyarakat umum pasti pernah melihat di muka umum disabilitas melakukan hal itu, padahal jika di kaji dalam tinjauan pendidikan bahwa kebutuhan seksual perlu diajarkan secara privat oleh keluarganya demi tidak menggangu masyarakat umum.

\section{Hak Pendidikan Penyandang Disabilitas Perspektif Hukum Perdata dan HAM}

Dalam pembukaan UUD 1945 alinea ke 4 sebetulnya sudah jelas bahwa tujuan Negara itu salah satunya adalah mencerdaskan kehidupan bangsa, sehingga untuk mencapai tujuan itu perlu adanya hak pendidikan yang terpenuhi bagi siapapun yang sekiranya Undang Undang tidak melarang. Pendidikan sangat diperlukan bagi semua elemen manusia agar hilangnya rasa bodoh dalam diri. Dalam pasal $3^{11}$ Undang Undang Nomor 20 Tahun 2003 sudah dijelaskan dengan sangat tartil, akan tetapi yang menjadi permasalahan adalah giroh memenuhi hak pendidikan bagi disabilitas masih dirasa kurang efektif.

Menurut Geny bahwa tujuan adanya hukum semata-mata hanya untuk menegakkan keadilan. Menurut Saint Agustine bahwa tujuan hukum itu adalah keadilan, jika bukan adil maka bukan hukum. Ada juga yang berpendapat bahwa tujuan hukum adalah manfaat, tertib dan tentram ${ }^{12}$. Dalam tinjauan hukum perdata bahwa ada konsep tentang subjek hukum. Menurut Komariah ${ }^{13}$ bahwa subjek hukum itu terdiri dari dua bagian, yaitu: manusia dan badan hukum atau dalam bahasa belandanya natuurkijke person dan recht person. Agar lebih spesifik, dalam penelitian ini lebih fokus kepada subjek hukum: manusia.

Semua kehidupan baik itu manusia, jagat raya dan fauna berawal dari Allah Swt sebagai penata dan sebagai bukti bahwa Allah itu Ada. Membicarakan manusia, manusia pertama yang diciptakan oleh Allah adalah Nabi Adam As dari tanah sedangkan manusia sebagai keturunannya diciptakan dengan melalui setetes sperma lalu berubah menjadi segumpal darah. Kemudian segala makhluk hidup yang ada di dunia ini pada dasarnya memiliki prinsip genetic atau berpasang-pasangan seperti ada yang baik dan yang buruk, jantan dan betina, hitam dan putih, atas dan bawah, gelap dan terang, siang dan malam, hidup dan mati, normal dan abnormal (disabilitas). Dari sekian banyak makluk tersebut memiliki komunitas atau kelompok sesuai dengan jenisnya seperti manusia memiliki komunitas/kelompok yang bergabung menjadi masyarakat. Dalam buku antropologi

11 Pendidikan nasional berfungsi mengembangkan kemapuan dan membentuk watak serta peradaban bangsa yang bermartabat dalam rangka mencerdaskan kehidupan bangsa, bertujuan untuk berkembangnya potensi peserta didik agar menjadi manusia yang beriman dan bertakwa kepada Tuhan Yang Maha Esa, Berakhlak Mulia, Sehat, Berilmu, Cakao,Kreatif, Mandiri, dan menjadi warga Negara yang demokratis serta bertanggung Jawab.

${ }^{12}$ Donald Albert Rumokoy, Pengantar Ilmu Hukum (Jakarta: Rajagrafindo, 2014), HIm. 27-35.

${ }^{13}$ Komariah, Hukum Perdata (Malang: UMM Press, 2010), hlm. 21-22. 
hukum $^{14}$ dikatakan bahwa pencpitaan manusia diatur oleh hukum Tuhan yang fitrah, artinya semenjak zaman azali telah ditetapkan.

Pada dasarnya manusia mulai dari kandungan sampai kepada meninggal selalu disertai dengan adanya hak. ${ }^{15}$ Manusia dapat melakukan perbuatan hukum selama tidak ada undang-undang yang melarangnya (pasal 1329 KUH Per). Dimana ada hak maka disitu ada kewajiban, dalam hal pemenuhan hak pendidikan bagi penyandang disabilitas sebetulnya itu sudah menjadi hak para penyandang disabilitas untuk mendapatkan sebuah ilmu melalui jalur pendidikan dan disisi lain sebagai kewajiban bagi guru atau orang tua untuk memenuhinya.

Walaupun secara aturan KUH Perdata tidak diatur pasal yang berkaitan dengan hak pendidikan. Akan tetapi dalam buku pertama KUH Perdata mengatur tentang orang atau manusia. Seperti pada pasal 1 yang berbunyi :"menikmati hak perdata tidaklah tergantung pada hak kenegaraan" artinya disini jika dikaitkan dengan pendidikan maka sebetulnya hak pendidikan itu sudah secara kodrati harus diberikan oleh guru atau orangtua. Pendidikan disini ditafsirkan secara luas seperti pendidikan berbasis agama atau non agama. Dengan tujuan agar menghilangkan kebodohan dalam diri sendiri. Dalam Al-Qur'an At-Taubah ayat 122 yang artinya ${ }^{16}$. Hal ini sebagai asas legalitas bagi semua manusia untuk mendapatkan hak pendidikannya, sebab menuntu ilmu tanpa guru ibarat mobil tanpa bensin.

Kemudian dalam hukum perdata dikenal dengan yang namanya asas perlindungan bagi manusia. Dalam asas ini menjadikan sebuah dasar hukum bahwa hak pendidikan bagi disabilitas merupakan sesuatu yang harus dilindungi oleh non disabilitas sebab, ketika kehadiran disabilitas dilingkungan sekitar menjadikan sebuah kewajiban bagi non disabilitas untuk membantu memenuhi segala hak yang berkaitan dengan keberlangsungan hidup bagi disabilitas tersebut.

Dalam Undang Undang Hak Asasi manusia di Indonesia yang diatur pada Nomor 39 Tahun 1999 mengatur segala aturan yang mengandung keperdataan yang menyangkut eksistensi manusia sebagai subjek hukum. ${ }^{17}$ Kemudian dalam konsep Hak Asasi Manusia bahwa pendidikan itu salah satu hak asasi manusia untuk memperolehnya. Menurut Bunadi Hidayat ${ }^{18}$ bahwa hak asasi manusia adalah hak bersifat universal. Jadi,

${ }^{14}$ Beni Ahmad Saebani and Encup Supriatna, Antropologi Hukum (Bandung: Pustaka Setia, 2012), HIm. 75-76.

${ }^{15}$ Djaja S. Meliala, Perkembangan Hukum Perdata Tentang Orang Dan Hukum Keluarga (Bandung: Nuansa Aulia, 2015), HIm. 21.

16 "Dan tidaklah sepatutnya orang-orang mukmin itu semuanya pergi kemedan perang, mengapa sebagaian diantara mereka tidak pergi untuk memperdalam ilmu pengetahuan agama mereka dan untuk memberi peringatan kepada kaumnya apanila mereka telah kembali, agar mereka dapat menjaga dirinya.

17 Muladi, Hak Asasi Manusia: Hakekat, Konsep Dan Implikasinya Dalam Perspektif Hukum Dan Masyarakat (Bandung: Refika Aditama, 2009), HIm. 162.

${ }^{18}$ Hidayat, HIm. 432. 
pendidikan itu berlaku bagi semua manusia tanpa ada sekat atau berlaku bagi golongan tertentu.

Jika dianalisis dalam pertimbangan Undang Undang Nomor 39 Tahun 1999 poin a bahwa ada nilai kodrati yang disebutkan dalam poin tersebut, sebab secara hakikatnya manusia diciptakan oleh Allah Swt yaitu untuk beribadah ${ }^{19}$. Tafsiran ibadah disini secara luas, yaitu ada 3 aspek yang mencakupinya yaitu aspek Allah (Habluminallah), manusia (Habluminannas) dan alam (Habluminal'alam). Jadi, 3 aspek ini terkandung dalam poin tersebut.

Kemudian pada poin 2 memberikan pesan kepada seluruh manusia untuk bisa menghargai dan mengakui keberadaan manusia yang lain. Sebab kepentingan seorang manusia dibatasi oleh kepentingan manusia yang lain. Kemudian jika mengabaikan atau bahkan memandang lemah, rendah manusia lain merupakan suatu tindakan yang murka yang melahirkan rasa kemarahan hati dan jiwa manusia.

Sebelum lahirnya Undang Undang Nomor 39 Tahun 1999 tersebut, ada pencetusan DUHAM (Deklarasi Universal Hak Asasi Manusia) yang bisa dikatakan menjadi titik awal adanya HAM. Dalam HAM tersebut dikatakan bahwa salah satu hak yang perlu dipenuhi adalah hak atas pendidikan sebagaimana di katakana pada Pasal 26 ayat (1). DUHAM atau UDHR merupakan hasil karya FBB yang menginginkan keberadaan sama rata dan sama rasa bagi setiap insan (disabilitas dan non disabilitas). Pada dasarnya setiap manusia non disabilitas akan menjadi disabilitas pada waktunya.

Artinya, setiap manusia akan merasakan kehilangan rasa nikmat anggota badan yang Allah titipkan. Seperti mata, ketika sudah tua maka akan rabu. Kaki yang tadinya sehat dan bahkan bisa berlari maka ketika sudah tua atau ada penyakit yang harus adanya imputasi maka akan ada kehilangan kemampuan untuk berjalan. Maka dari itu penulis lebih setuju pemanggilan kelompok tersebut dengan disabilitas dibandingkan dengan difabel atau cacat. Alasannya, jika difabel merupakan singkatan dari kata different ability yang maknanya "perbedaan kemampuan" dan ini kurang tepat karena setiap disabilitas memiliki kemampuan yang sama akan tetapi caranya berbeda.

Contoh setiap manusia memiliki kemampuan yang sama antara non disabilitas dengan disabilitas (tunadaksa) akan tetapi membutuhkan kursi jalan atau tongkat untuk membantunya. Jika cacat itu sudah tidak manusia, sebab dari penamaannya juga sudah melahirkan stigma negative dari awal. Kemudian disabilitas itu sendiri menurut WHO bahwa disabilitas itu secara sederhananya memiliki unsur "hilangnya kemampuan" sehingga ketika lingkungan mendungkung atau memberikan support maka kehilangan tersebut akan pudar bahkan benar-benar hilang.

${ }^{19}$ Os. Adz Dzariyat ayat 56 yang artinya "Tidaklah aku ciptakan jin dan manusia melainkan supaya mereka menyembah-KU". 
Kemudian pada Undang Undang Nomor 39 Tahun 199 Tentang HAM yang menjanjikan akan sebuah kebolehan untuk mengexplore diri agar menjadi berkualitas (Pasal 12). Dan pada Pasal 42 setiap insan disabilitas diberikan hak untuk menggapai pendidikan. Sebetulnya Undang Undang ini ketika adan sebuah ketetapan dari MPR tahun 1998 yang mana merespon adanya UDHR sebagaimana yang telah diuraikan diatas.

Pada dasarnya ketika dianalisis lebih mendalam bahwa pendidikan salah satu Hak Asasi Manusia bisa ditemukan di dalam Undang Undang No 20 Tahun 2003 tentang Sitem Pendidikan Nasional. Dalam aturan ini menjadi sebuah pendukung dalam memenuhi segala hak bagi disabilitas khususnya pendidikan. Terbukti dalam pasal 5 mengatakan bahwa setiap warga Negara berhak mendapatkan pendidikan dan pada pasal 32 berbunyi setiap insan yang memiliki keterbatasan seperti fisik, mental dan lain-lain berhak mendapatkan pendidikan.

Diterima atau tidak, pendidikan sudah menjadi sebuah kebutuhan rohani demi menjaga eksistensi kefitrahan seorang manusia. Perlu ditekankan bahwa untuk menjaga eksistesi tersebut melalui pendidikan, bukan hanya khusus milik manusia non disabilitas melainkan disabilitas juga berhak mendapatkannya. Bagi non disabilitas, memberikan stigma positif sudah menjadi lingkungan ramah bagi disabilitas agar bisa memenuhi segala hak yang dibutuhkan.

Sehingga hukum perdata dan Hak Asasi Manusia pada dasarnya sangat mendukung untuk lingkungan (keluarga dan sekolah) yang menjadi sarana atau wasilah untuk bisa lebih efektif dan berkualitas dalam memberikan hak pendidikan bagi penyandang disabilitas.

\section{Kesimpulan}

Dari penjelasan-penjelasan yang terdapat pada uraian diatas, maka dapat ditarik kesimpulan sebagai berikut: Bahwa pemenuhan hak pendidikan masih bisa dibilang kurang terpenuhi bagi sebagai penyandang disabilitas yang ada di Indonesia terlepas dari karena faktor internal atau eksternal. Bahwa dalam aspek hukum perdata terdapat kandungan Hak Asasi Manusia dan begitupun sebaliknya sehingga secara hukum hak pendidikan bagi penyandang disabilitas sangat berdasarkan hukum dan patut secara penegakkannya harus di implementasikan. 
Anonimous. "Demokrasi, HAM, Masyarakat Madani, Pada Tanggal 23-07-2019, Pukul 20:00 WIB.," 2011.

Budiardjo, Miriam. Dasar-Dasar Ilmu Politik. Jakarta: Gramedia Pustaka Utama, 2008.

Davison, Gerald C. Psikologi Abnormal. Jakarta: Rajagrafindo, 2006.

Hidayat, Bunadi. Perlindungan Hak Asasi Manusia Sebagai Proses Pengembangan Hukum Modern Di Indonesia. Jakarta: Yuridika, 2006.

Komariah. Hukum Perdata. Malang: UMM Press, 2010.

Meliala, Djaja S. Perkembangan Hukum Perdata Tentang Orang Dan Hukum Keluarga. Bandung: Nuansa Aulia, 2015.

Mertokusumo, Sudikno. Teori Hukum. Yogyakarta: Cahaya Atma Pustaka, 2012.

Muladi. Hak Asasi Manusia: Hakekat, Konsep Dan Implikasinya Dalam Perspektif Hukum Dan Masyarakat. Bandung: Refika Aditama, 2009.

Partai Keadilan Sejahtera, DPP. "Hak Pendidikan Bagi Penyandang Disabilitas Sulit Terakomodir." Berita PKS, 2018. http://pks.id/content/hak-pendidikan-bagipenyandang-disabilitas-sulit-terakomodir (Diakses Pada Tanggal 23-07-2019 Pukul 15:15 Wib).

Primastika, Widia. "Penyandang Disabilitas Masih Sulit Mengakses Perguruan Tinggi." tirto.id, 2018. https://tirto.id/penyandang-disabilitas-masih-sulit-mengaksesperguruan-tinggi-c6am diakses pada tanggal 23-07-2019 Pukul 15.10 Wib.

Rachman, Fachmi. "Reka Ulang Pembunuhan Sadis Di Balikpapan Terkendala Komunikasi, Ini Penyebabnya Artikel Ini Telah Tayang Di Tribunkaltim.Com." kaltim.tribunnews.com, 2013. https://kaltim.tribunnews.com/2019/07/13/rekaulang-pembunuhan-sadis-di-balikpapan-terkendala-komunikasi-ini-penyebabnya (diakses pada tanggal 23-07-2019 Pukul 15.00 Wib).

Rumokoy, Donald Albert. Pengantar Ilmu Hukum. Jakarta: Rajagrafindo, 2014.

Saebani, Beni Ahmad, and Encup Supriatna. Antropologi Hukum. Bandung: Pustaka Setia, 2012.

Walukow, Julita Melissa. "Perwujudan Prinsip Equality Before The Law Bagi Narapidana Di Dalam Lembaga Permasyarakatan Di Indonesia." Jurnal Ilmiah Lex et Societatis Volume 1, no. 1 (2013). 
256 | Asy-Syari'ah Vol. 21 No. 2, Desember 2019 


\begin{abstract}
Asy-Syari'ah (P-ISSN : 2086-9029 E-ISSN: 2654-5675) is a periodical scientific journal that publishes various results of studies and research, literature review, and other scientific works whose scope covers the field of Islamic law/sharia, law and society in monodisciplinary, interdisciplinary, and multidisciplinary manners. The journal aims to expand and create innovative concepts, theories, paradigms, perspectives and methodologies in the above said scope. The Journal is published twice a year (june and december) by Faculty of Shariah and Law, Sunan Gunung Djati State Islamic University Bandung in collaboration with Asosiasi Sarjana Syariah Indonesia (ASSYI).
\end{abstract}

\title{
EDITORIAL OFFICE:
}

Fakultas Syariah dan Hukum UIN Sunan Gunung Djati Bandung Jl. Raya A.H. Nasution No. 105 Cibiru Kota Bandung, 40614

Tlp/Fax: +022-7802278 Faks. 022-7802278

Website http://journal.uinsgd.ac.id/index.php/asy-syariah/index

E-mail: Jurnalasy-syariah@uinsgd.ac.id 